\title{
PARA DANÇAR [COM] A CIDADE: EM BUSCA DE CARTOGRAFIAS URBANAS EMERGENTES
}

\author{
lale Luiz Moraes Camboim*
}

Resumo: 0 presente artigo explora as potencialidades de uma proposta de intervenção artística efêmera para ser realizada em espaços públicos da cidade. A partir dos achados da minha pesquisa de mestrado, intitulada Dançar [com] a cidade: mapeamentos sensiveis da experiência urbana contemporânea (CAMBOIM, 2017), mobilizo uma série de conceitos interdisciplinares para reforçar uma ideia de cidade como lugar da simultaneidade; uma ideia de corpo, maleável, poroso às afetações do seu entorno, em constante mutação; e uma ideia de dança, feita na rua e com a rua. Assim, dedico-me ao estudo das relações entre corpo e cidade a partir da experiência de criação dessa "dança situada". Com base nesses conceitos, pude conceber uma pauta coreográfica para dançar [com] a cidade. Essa pauta, impressa em forma de lambe, foi afixada em alguns espaços públicos de três cidades: São Paulo - SP, Recife - PE e João Pessoa - PB. Em cada uma dessas cidades, segui as instruções da pauta e realizei a proposta de intervenção. Ao longo do texto, exponho os conceitos que deram origem à intervenção e relato as experiências das danças geradas nos três espaços públicos escolhidos. Por meio da pauta coreográfica, convido as pessoas a dançarem [com] suas cidades e a registrarem suas experiências, refletindo sobre o que fica gravado nos seus corpos como rastro de uma vivência corporificada.

Palavras-chave: Dança situada. Corpo. Espaço público. Cartografias urbanas emergentes. Pauta coreográfica.

\section{CONSIDERAÇÕES INICIAIS}

Este texto apresenta e discute uma proposta de intervenção artística efêmera em espaços públicos da cidade - uma intervenção que busca fortalecer determinadas ideias de cidade, de corpo e de dança, as quais serão explicadas posteriormente. Para a formulação dessas ideias, mobilizei uma série de conceitos heterogêneos que auxiliaram na concepção de uma pauta coreográfica para dançar [com] a cidade. Aqui, retrato como se deu o processo de criação

\footnotetext{
* Doutorando em Arquitetura e Urbanismo pela Universidade Federal da Bahia (UFBA). Mestre em Arquitetura e Urbanismo pela UFPB. Na mesma universidade desenvolveu atividades artisticas e de pesquisa com o grupo Radar 1, coletivo de artistas que busca investigar a performance artística contemporânea e processos de criação interdisciplinares, com foco nas relações que se estabelecem entre corpo e cidade. E-mail: ialecamboim@gmail.com
} 
dessa pauta - tendo as suas próprias instruções como tópicos estruturadores do texto - e relato algumas ações artísticas motivadas por ela e vividas em três diferentes cidades brasileiras: São Paulo - SP, Recife - PE e João Pessoa - PB.

Esta proposta tem origem nas experiências vivenciadas no âmbito da pós-graduação em Design e Arquitetura de Espaços Efêmeros (Daee), entre os anos de 2014 e 2015, e da minha pesquisa de mestrado, intitulada Dançar [com] a cidade: mapeamentos sensiveis da experiência urbana contemporânea (CAMBOIM, 2017), desenvolvida junto ao Programa de Pós-Graduação em Arquitetura e Urbanismo da Universidade Federal da Paraíba (PPGAU-UFPB), entre 2015 e 2017. As discussões levantadas pelos módulos, as diversas leituras e outras experiências artísticas pessoais, principalmente na área de dança, alimentaram o processo criativo em torno deste trabalho.

\title{
FECHA OS OLHOS/SENTE O CHÃO SOB TEUS PÉS/DESPERTA
}

Diante do nosso contexto urbano contemporâneo, defendo uma ideia de uma cidade que é sinônimo de multiplicidade e pluralidade, a qual, segundo o sociólogo francês Henri Lefebvre (2012, p. 70), manifesta-se como um "grupo de grupos, com sua dupla morfologia": materialidade e espaço social.

\begin{abstract}
A forma do espaço social é o encontro, a reunião, a simultaneidade. 0 que se reúne? 0 que é reunido? Tudo que há no espaço, tudo que é produzido, seja pela natureza, seja pela sociedade - seja por sua cooperação, seja por seus conflitos. Tudo: seres vivos, coisas, objetos, obras, signos e simbolos (LEFEBVRE, 2000, p. 121, tradução nossa).
\end{abstract}

A cidade que é produzida pelo planejamento urbanístico afeta diretamente as dinâmicas e os arranjos dos grupos sociais no espaço urbano, especialmente nos seus espaços públicos, lugares da vida cotidiana, da apropriação coletiva e do encontro com as diferenças. Para o geógrafo Milton Santos (2013), a copresença no espaço da cidade ensina os homens a lidarem com o diferente, é lugar de aprendizado. Essa qualidade do espaço público acaba sendo a mais prejudicada mediante a lógica dos atuais processos de produção das cidades, fortemente influenciada pela cultura globalizada:

\footnotetext{
0 espaço é hoje um sistema de objetos cada vez mais artificiais, povoados por sistemas de ações igualmente imbuidos de artificialidade, e cada vez mais tendentes a fins estranhos, ao lugar e a seus habitantes [...]. Refiro-me, sobretudo, aos objetos novos, àqueles que formam os sistemas hegemônicos, surgidos para atender às necessidades das ações hegemônicas (SANTOS, 2013, p. 86).
} 
Atualmente, a qualidade de vida urbana tornou-se uma mercadoria para aqueles que têm dinheiro, num mundo no qual o consumismo, o turismo e a espetacularização dos espaços passam a mover a economia política urbana. David Harvey $(2014$, p. 47) acredita que "a ética neoliberal do intenso individualismo [...] pode transformar-se em um modelo de socialização da personalidade humana. Seu impacto vem aumentando o individualismo isolacionista, a ansiedade e a neurose".

A essa atual realidade das cidades, podemos relacionar o processo mais vasto de espetacularização urbana contemporânea. A cidade, hoje, é pensada como uma peça de marketing, um modelo mercadológico global e sui generis. Tudo é fruto de uma imagem criada, verdadeiros cenários, com o objetivo de manipular o gosto e a opinião, enquanto as experiências urbanas sensiveis e corpóreas minguam. Os atuais projetos urbanos, principalmente aqueles ditos de revitalização, são quase sempre espetaculares, no sentido de que negam os conflitos e dissensos da esfera pública e tentam reduzir ou eliminar a vitalidade popular dos espaços da cidade, transformando-os em ambientes ordenados, assépticos e sem vida (JACQUES, 2014).

Por isso, procuro me aproximar das forças da cidade que persistem no "embaixo" e resistem às estratégias de um planejamento urbano excludente. A orientação dada pela pesquisadora Ana Clara Torres Ribeiro (2011), nesse sentido, é de que passemos a estudar a cidade contemporânea a partir da construção de uma cartografia da ação, que valorize a experiência social e registre a transformação dos lugares em verdadeiramente usados, praticados e vivenciados. Para a pesquisadora,

a cidade viva e experimental não morreu, apesar de todas as afirmações em contrário, feitas pelo discurso da crise. Ela é fortíssima, muito resistente. Daí a importância dos sujeitos sociais, que, de fato, existem, nas suas condições eventuais de sujeitos da sua própria ação, e que, na verdade, são as pessoas que estão nas ruas, falando, dizendo, agindo, fazendo. É essa a cartografia da ação a que nos referimos (RIBEIRO et al., 2011, p. 31).

Por volta dos anos 1950, um grupo de teóricos e artistas - nomeado de Internacional Situacionista (IS) - se reuniu com o objetivo de lutar contra o capitalismo espetacular, a forma como as cidades vinham sendo construídas e as implicações negativas desse processo na vida cotidiana dos citadinos. Os situacionistas propunham uma série de ferramentas desviatórias como forma de apreender o espaço urbano e ir de encontro à lógica da produção espetacular da cidade. Dentre essas ferramentas, destaco a ideia de deriva como experiência efêmera para a construção de situações. Na verdade, toda a base do pensamento urbano situacionista encontrava-se na construção dessas situações, que seria a construção momentânea de novas ambiências com base em intervenções planejadas no espaço da cidade. A deriva, aqui, trata-se de uma prática que utiliza o corpo como dispositivo sensorial, capaz de questionar a lógica hegemônica do espaço urbano espetacular (DEBORD, 2003). 
Segundo o texto "Questões preliminares à construção de uma situação", do IS, uma situação "é feita de gestos contidos no cenário de um momento. Gestos que são o produto do cenário e de si mesmos. Produzem outras formas de cenários e outros gestos" (INTERNACIONAL SITUACIONISTA, 2003, p. 62). A construção de situações tem sua origem inteiramente experimental e busca estabelecer um campo de atividades temporárias que respondem aos desejos que puderam ser identificados nessa experimentação. Uma situação construida no espaço pode esclarecer os desejos que a originaram ou até mesmo provocar o aparecimento de novos desejos. Seria uma "nova realidade constituida pelas construções situacionistas" (INTERNACIONAL SITUACIONISTA, 2003, p. 62).

Uma situação deve ser sempre uma construção coletiva. Ainda que, inicialmente, haja um projeto de situação pensado por um "roteirista", esse deve estar ciente das intervenções que essa situação sofrerá quando ela for vivida coletivamente, inclusive por espectadores que não participaram do seu processo de construção. 0 público não é mais passivo, apenas observador alheio àquele acontecimento; ao contrário, ele deve sentir-se convidado à ação coletiva - um convite à experiência da cidade.

É a ação do(s) corpo(s) no espaço público urbano a maior responsável por essa contraprodução da cidade. Nesse aspecto, destaco o entendimento de que "a experiência urbana fica inscrita em diversas escalas de temporalidade, do próprio corpo daquele que a experimenta, e dessa forma também o define, mesmo que involuntariamente" (JACQUES, 2008). Com isso, as pesquisadoras Fabiana Britto e Paola Jacques (2008) explicam o que elas passaram a chamar de corpografia urbana. Trata-se de uma cartografia da cidade que fica gravada nas práticas corporais dos seus habitantes (uma corpo-cartografia, por isso o neologismo corpografia).

Essa concepção de corpografia urbana está atrelada a um determinado conceito de corpo. A pesquisadora Christine Greiner (2005) fornece-nos pistas importantes de como devemos considerar o corpo em trabalhos contemporâneos. Sua primeira indicação diz respeito ao ponto de vista segundo o qual corpo e mente são unidades indissociáveis. 0 dualismo entre mente e corpo tem origem no pensamento cartesiano e está refletido no binômio teoria-prática. "Pensamos e aprendemos com o corpo todo e não apenas com o cérebro e o sistema nervoso" (GREINER, 2005, p. 48).

0 segundo aspecto elementar que devemos considerar diz respeito a uma não distinção do corpo anatômico e do corpo vivido que atua no mundo. São elementos que estão atrelados um ao outro. Corpo e ambiente interagem em processos coevolutivos, o que "significa dizer que não é apenas o ambiente que constrói o corpo, nem tampouco o corpo que constrói o ambiente. Ambos são ativos o tempo todo" (GREINER, 2005, p. 43). Em sintonia com essa reflexão, David Harvey (2011) sugere que o nosso corpo deve ser entendido como um projeto inconcluso e, de certo modo, maleável, em constante evolução, transformando-se como efeito de diversos processos externos e vice-versa. Ademais, 
o corpo não é uma unidade fechada e lacrada, mas algo relacional, poroso em relação ao ambiente.

Logo, refiro-me a uma ideia de dança que agrega essas noções de corpo e que é feita na rua, com a rua. Essa dança é entendida como prática social, dado que, nas palavras da arquiteta e urbanista Vera Pallamin (2000, p. 23-24), as obras de arte urbana "permitem a apreensão de relações e modos diferenciais de apropriação do espaço urbano, envolvendo em seus propósitos estéticos o trato com significados sociais que as rodeiam, seus modos de tematização cultural e política". Por isso, considero a dança um dispositivo sensível que coloca o(s) corpo(s) em evidência, buscando gerar novas experiências e, consequentemente, novas narrativas acerca dos conteúdos sociais e materiais do espaço urbano, muito semelhante às experiências situacionistas. Esse tipo de dispositivo artístico está inserido no campo da dança conhecida como site-specific, ou dança in situ, e expressa a ideia de uma dança criada a partir de e para uma determinada realidade espacial (MORAIS, 2015).

Na tese de Líria de Araújo Morais (2015), a dançarina elucida que site-specific e in situ são termos emprestados das artes visuais para classificar a dança que apresenta as características descritas acima. No entanto, as reflexões sobre a especificidade do lugar nas obras de arte se apresentam de maneiras distintas nas artes visuais e na dança. Ela explica que, com a utilização dessas nomenclaturas, "corre-se o risco de generalização e classificação de todas as danças feitas fora dos palcos como um tipo de composição que se alinha enquanto modo de fazer, apenas por estar fora desses ambientes" (MORAIS, 2015, p. 30). Contudo, nem sempre as danças fora do palco são para estabelecer um diálogo com o contexto espacial no qual estão inseridas. Assim, para evitar generalizações que a aplicação desses termos possa causar, Líria Morais refere-se a esse tipo de dança como uma composição situada.

Na composição situada, quando o público não mais é considerado espectador, mas, sim, participador das ações, inevitavelmente se agrega o viés da improvisação. A improvisação em processos criativos de dança pode ser utilizada como método ou um fim em si mesmo, quando a obra preserva esse caráter em todos os seus momentos. Nesse segundo caso, a formulação, execução e exibição da obra ao público ocorrem simultaneamente (PASSOS, 2015). Para complementar o entendimento de dança improvisada, a dançarina Suzi Weber assinala que essa prática compositiva trabalha com movimentos que não são preestabelecidos como uma partitura coreográfica fixa. No entanto, as ações do corpo ao improvisar não surgem de repente, elas trazem organizações e composições de movimentos já experimentadas anteriormente, ideias que já foram visitadas (WEBER, 2015, p. 11-22). Na dança que proponho, quando a motivação para a composição em dança se dá no meio urbano, em seus espaços públicos, o dançarino parece jogar com os resquícios da experiência urbana gravadas no seu corpo, suas corpografias. 


\section{DESLOCA-TE PELO ESPAÇO/BUSCA O OLHAR DAS PESSOAS AO TEU REDOR}

0 processo de criação da composição situada acontece em tempo real, no contexto de um lugar específico, articulando-se para além de seu aspecto físico, mas também com os aspectos políticos, históricos e simbólicos do espaço. As instruções da pauta coreográfica foram pensadas como motivações para a construção de relações entre corpo e cidade, não para serem seguidas à risca. São instruções em aberto, como bem aponta Hélio Oiticica (2012):

Contato não contemplativo. Espectador transformado em participador. Proposições em vez de peças. Propor. Propor práticas não ritualísticas. 0 artista não mais como criador de objetos, propositor de práticas. Descobertas apenas sugeridas, em aberto. Proposições simples e gerais não ainda completadas. Situações a serem vividas.

0 participador cria a sua própria obra e constrói relações a partir do contexto no qual suas ações estão inseridas. Paul Ardenne (2002), historiador de arte francês, explica que a arte contextual presume a materialização das intenções de um artista em um contexto particular, no caso, a realidade. Porém, ao se apropriar da realidade para a criação artística, o artista passa a explorar um território muito mais vasto do que sua própria arte, jogando-se numa aventura que não o pertence e que não está sob seu comando. É impossivel determinar previamente a recepção do seu público, as consequências da sua obra, muito menos se serão positivas. Há, em todo caso, um aspecto obrigatório, impossível de ser contornado: o da experiência concreta.

A primeira razão de ser da arte contextual surge de um desejo social: intensificar a presença do artista na realidade coletiva. Isso se dá de múltiplas formas - se apropriá-la, estetizá-la, politizá-la... -, mas sempre dentro de uma perspectiva de implicação. A ideia-chave: o mundo existe para que o artista apareça nele ao vivo, sem intermediário, ao mesmo tempo que sua obra é a oportunidade de uma troca direta com o campo da realidade (ARDENNE, 2002, p. 41).

Alinhado a essas ideias, Nicolas Bourriaud (2009, p. 18) tenta explicar o que ele identificou como um principio frequente, o espírito que anima a arte que é feita hoje. Para ele, "as obras já não perseguem a meta de formar realidades imaginárias ou utópicas, mas procuram constituir modos de existência ou modelos de ação dentro da realidade existente, qualquer que seja a escala escolhida pelo artista". Ações artísticas caracterizadas por uma estética relacional buscam criar ou estimular novas formas de viver socialmente.

Além do referencial teórico exposto até aqui, as experiências de criação da dança situada - empreendidas durante a minha pesquisa de mestrado - revelaram que o corpo em criação está sujeito a um processo, o qual tentei sintetizar com uma sequência de cinco ações: despertar, deslocar, impregnar, provocar e ampliar. 
Resumidamente, o despertar dá-se na forma de um refinamento da consciência corpo-espaço, sobretudo quanto à atenção ao aspecto de simultaneidade da realidade urbana. É preciso, primeiramente, buscar uma postura consciente do lugar do nosso corpo no mundo. Entendo, ainda, caminhar e deslocar-se pelo espaço como a forma mais básica de relacionar corpo e ambiente, haja vista as reflexões sugeridas por artistas e pensadores que propunham experiências urbanas errantes como práticas estéticas.

0 impregnar-se do lugar é rastrear no corpo os afetos gerados pela experiência sensivel. Significa incorporar a ética de um determinado espaço e identificá-la como um conjunto de leis que regem as relações que ali são construídas. A memória do corpo, resquícios da experiência vivida, é constantemente consultada seguindo uma lógica de reciprocidade entre corpo e espaço, no momento da composição situada. A motivação para a improvisação passa a ser a simultaneidade das relações que vão sendo tecidas no momento da composição. 0 ato de provocar mistura-se ao impregnar, uma vez que a própria ação do corpo no espaço público gera perturbações no ambiente. Os movimentos gerados na dança intervêm no espaço seguindo uma lógica relacional, muitas vezes desviante, produzindo novas realidades. Assim, ao mesmo tempo que a dança modifica algumas lógicas inerentes ao espaço, ela também sofre constantes reajustes para adaptar-se às novas realidades criadas.

Nessa perspectiva processual, o verbo ampliar aparece quase de forma pleonástica. Acredito que com esse tipo de experiência artística podemos ampliar as possibilidades de viver e conviver na cidade. Ampliando, assim, a compreensão do outro e de nós mesmos enquanto sujeitos da nossa ação no mundo.

\section{IMPREGNA A CIDADE NO TEU CORPO}

Em referência a esses cinco verbos, desenvolvi uma pauta coreográfica com cinco instruções básicas que permitem a livre apropriação e interpretação por quem as lê. Em seguida, transformei a pauta em um lambe para ser espalhado e afixado pelos lugares por onde passo (Figura 1). Também enviei a pauta para pessoas conhecidas, por e-mail, e coloquei outras em caixas de correio aleatórias. Nas instruções, peço às pessoas que registrem, de algum modo, suas experiências dançadas e enviem para um e-mail criado especialmente para coletar esse material. ${ }^{1}$ 
Figura 1 Registros da colagem dos lambes com a pauta coreográfica

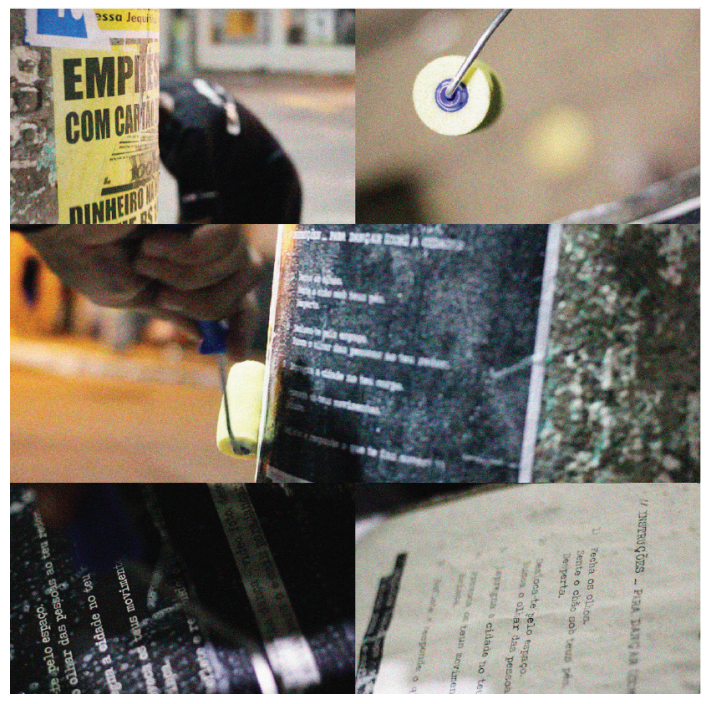

Fonte: Acervo do autor.

Interessa-me, igualmente, investigar as diversas formas de registro dessas experiências, outros modos de cartografar a cidade. A fotografia, o vídeo, o áudio, o relato escrito, o desenho são apenas alguns exemplos de materiais que podem gerar cartografias emergentes, pois empenham-se em registrar os estados transitórios do(s) corpo(s) na cidade, as ações e relações construídas socialmente, os conflitos, os acordos e as surpresas que emergem com a experiência dos espaços públicos urbanos.

Uma vez preparada a pauta coreográfica, de posse dos lambes, empenhei-me em realizar essa dança em espaços públicos que pudessem indicar diferentes percepções da cidade. No entanto, havia uma característica primordial e comum a todos os espaços "dançados": a existência de uma vitalidade popular. Se meu objetivo também era construir relações com as pessoas que vivem o espaço público, eu precisava me aproximar dos lugares que de algum modo preservassem essa vida pública.

\section{São Paulo (Praça Roosevelt)}

Na ocasião de minha passagem pela cidade de São Paulo, em julho de 2017, aproveitei para dançar as instruções da pauta num espaço público de meu interesse. Escolhi a Praça Roosevelt, localizada na região central da capital paulista, por se tratar de um lugar que apresentava as características descritas acima. Além disso, eu já havia frequentado a praça em outros poucos momentos e a variedade de pessoas que a ocupavam, de diferentes faixas etárias, estilos e gêneros, me chamou a atenção. Meu olhar não era mais de estrangeiro, 
porém eu não conhecia profundamente o contexto urbano no qual a praça se insere, suas disputas sociais, seu histórico. Nesse aspecto, eu apenas sabia que o espaço havia sido reformado recentemente, há aproximadamente cinco anos, após passar por um período de degradação. Dançar naquele ambiente, da forma que a pauta coreográfica sugere, me ajudaria a criar uma imagem do lugar - mais uma. Dessa vez, seria uma imagem atualizada a partir da experiência corporal motivada pela ação artística.

Era a primeira vez que eu dançava sozinho na rua. Todas as minhas experiências anteriores de performances artísticas urbanas haviam sido construidas em conjunto com outros(as) artistas. No entanto, antes de iniciar a dança, entendi que eu não dançaria "sozinho", mas com tudo aquilo que se apresentava ao meu redor: materialidade, sons, olhares, interpelações, fluxos...

Era uma tarde de sábado e a praça estava ocupada por jovens, muitos deles skatistas e ciclistas, famílias inteiras, crianças que brincavam por todo o espaço, grupos de adultos que se reuniam em rodas de conversa. Havia um grupo de mulheres que, pelo que pude ouvir, parecia discutir questões feministas. Muitas pessoas praticavam corrida, andavam de patins, bebiam com amigos. Direcionei-me ao centro de um canteiro gramado onde havia uma área circular formada por grades vermelhas. Se olhasse pelas brechas da grade, poderia ver o pavimento inferior da praça. Caminhar por ali me dava uma impressão de estar flutuando, ao mesmo tempo que me assustava perceber a altura das grades em relação ao piso inferior. A materialidade particular desse círculo vermelho me atraiu e no seu centro dei início à minha dança (Figura 2).

Figura 2 Registros da performance na Praça Roosevelt, em São Paulo

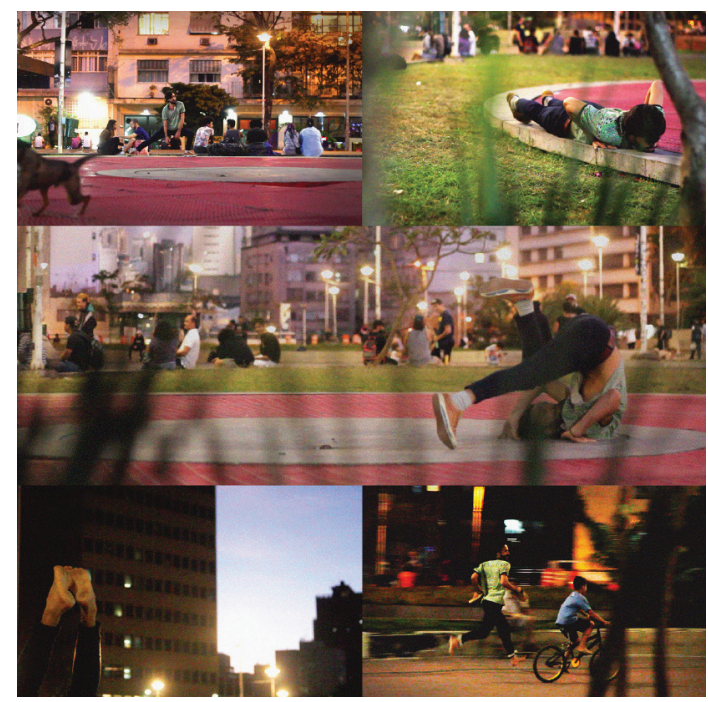

Fonte: Fotografia de Dessa Ocker. Edição e montagem do autor. 
Comecei de olhos fechados, tentando identificar o máximo de sons possiveis naquela confusão de ruídos. Abri os olhos e lentamente comecei a me movimentar guiado pelos estímulos sonoros e pelas formas do espaço. Segui as orientações da pauta coreográfica e aos poucos fui ampliando a intensidade das minhas movimentações. Impressionou-me a escala da praça, e seu entorno, em relação ao meu corpo. Senti-me pequeno demais, quase imperceptivel. Inicialmente, criar relações com as pessoas à minha volta foi uma tarefa dificil. Algumas pareciam estar mais preocupadas com os seus mundos e outras, acostumadas com esse tipo de intervenção artística. Demorei para encontrar o olhar daquelas pessoas.

Em um dado momento, percebi que duas crianças me observavam curiosas. Cheguei perto delas e, sem falar, demonstrei que queria apostar uma corrida. Comecei a correr pela praça e os dois meninos, em suas bicicletas, vieram atrás de mim. Corri enquanto meu fôlego aguentou. A essa altura, eu já estava descalço e corria com as meias amarradas nas pernas. Voltei para o círculo vermelho e finalizei a minha ação me sentindo um pouco mais familiarizado e acolhido por aquele espaço.

\section{Recife (Praça do Diário)}

Alguns dias após a minha visita a São Paulo, cheguei em Recife para um encontro com a equipe do grupo Pesquisa e Inovação para as Cidades (Inciti), um grupo transdisciplinar vinculado à Universidade Federal de Pernambuco (UFPE), cuja sede está localizada no Bairro do Recife. 0 objetivo dessa visita era falar um pouco sobre as minhas pesquisas e apresentar a ideia desta pauta coreográfica. Era uma tarde de quarta-feira e fiquei positivamente surpreso quando percebi que boa parte da equipe estava disposta a ir à rua comigo, naquela mesma tarde. Eu havia levado alguns lambes e pedi que o grupo me ajudasse a colá-los por onde passássemos. Expliquei que eles não iam apenas me observar dançar, mas que também participariam da ação.

Saímos às ruas e o primeiro lugar sugerido pelo grupo para ser local da nossa intervenção foi a praça do Marco Zero. Receei essa escolha, pois sabemos quanto esse espaço tem sofrido com ações pacificadoras, com a turistificação, sempre na lógica dos chamados processos de revitalização urbana. Realizar a intervenção no Marco Zero poderia ser interessante, justamente para contrapor essa lógica imposta ao lugar, mas eu buscava um espaço que estivesse mais conectado ao cotidiano do cidadão recifense. Saímos andando pelas ruas do centro e colamos alguns lambes pelo caminho. Surgiu, então, a ideia de irmos até a Praça da Independência - mais conhecida como Praça do Diário. Ao chegar à praça, o espaço pareceu-me intensamente familiar, pois assemelhava-se a vários espaços públicos do centro de João Pessoa, onde eu já havia dançado. Sugeri aos que estavam comigo que ficassem à vontade para deslocar-se pela praça, para seguir as instruções da pauta, ou não, mas que buscassem construir relações com o que se apresentava ali, pessoas e objetos (Figura 3). 
Figura 3 Registros da performance na Praça do Diário, no Recife

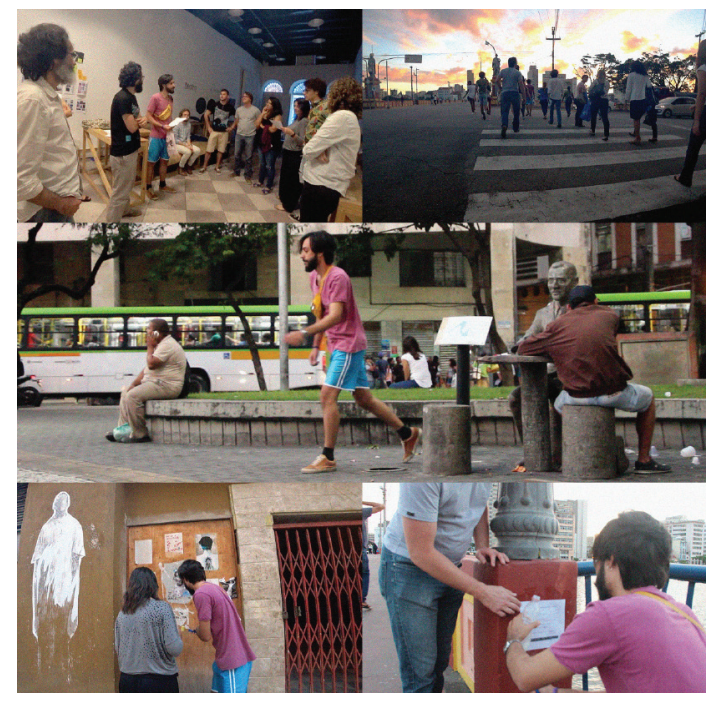

Fonte: Acervo do autor.

A Praça do Diário é um espaço extremamente vivo. Viamos vendedores ambulantes, transeuntes, pessoas apinhadas nos pontos de ônibus, moradores de rua, prostitutas em busca de clientes, crianças, jovens e idosos... todos dividindo o mesmo espaço. Comecei a caminhar lentamente pela praça e, a partir desse deslocamento, deixei-me impregnar pelo lugar, permiti que o meu corpo fosse afetado pelos conteúdos do ambiente. Antes de dar origem a qualquer movimentação, é importante construir uma memória corporal que absorve os aspectos menos explícitos do lugar. Caminhei até o centro da praça, fechei os olhos e reparei na diversidade dos seus sons.

Comecei a me movimentar pela praça buscando provocar tensionamentos, estranhamentos e fricções entre diferentes realidades que se apresentavam ali. Um homem, que parecia estar bêbado, colocava música em uma caixinha de som. Aproximei-me e, lentamente, dei início a uma dança ao som daquela música. Percebi os olhares curiosos ao meu redor. No momento, eu me perguntava se o mesmo estranhamento seria causado caso eu fosse um morador de rua, ou outro bêbado maltrapilho, em vez de um homem branco de aparência bem cuidada. Agradeci ao homem que colocava a música e saí correndo para outro lado da praça.

Sentei-me em um banco de concreto e uma mulher, sentada ao meu lado, puxou assunto. Ela era prostituta, disse que o movimento de clientes naquele dia estava difícil, tudo estava dificil, mas que o importante era estar com saúde. Concordei e conversamos mais um pouco. Em um dado momento, comecei a interagir com o pessoal do Inciti, que estava espalhado pela praça. Natan me ensinou alguns movimentos de artes marciais. A partir disso, Pedro e 
eu começamos uma dança improvisada que evoluiu para uma brincadeira. Quando menos esperávamos, toda a praça estava envolvida numa brincadeira de pega-pega. Mesmo quem não estava brincando estava envolvido com olhares ou com risadas.

Já era noite quando decidi iniciar a caminhada de volta ao Inciti. Percebi que se dependesse de alguns integrantes do nosso grupo, teríamos ficado por mais algumas horas naquela brincadeira. Em pouco tempo, a praça havia se tornado um quintal de casa.

\section{PROVOCA OS TEUS MOVIMENTOS/BRINCA}

Essas experiências em São Paulo e Recife mostraram-me que as instruções da pauta coreográfica, no momento da dança, não precisam ser seguidas de forma sequencial. Elas se atravessam, podem ser simultâneas ou em uma ordem embaralhada. Por exemplo, ao mesmo tempo que eu provoco os meus movimentos e brinco com os elementos do espaço, também estou me deixando impregnar pela cidade, criando rastros de experiência no meu corpo. Por essa razão, entendo a pauta como motivadora de experiências, cada espaço estimula o aparecimento de ações distintas. Deixar as movimentações emergirem ao longo do processo faz muito mais sentido do que tentar seguir à risca as instruções que foram colocadas.

\section{João Pessoa (Praça Rio Branco)}

De volta a João Pessoa, cidade onde resido, decidi ir ao bairro do Centro para desenvolver mais uma dança baseada na pauta coreográfica. Escolhi a Praça Rio Branco por considerá-la convidativa. As suas grandes árvores, seus bancos e entorno arquitetônico são um convite à permanência. Como era uma segunda-feira à tarde, eu sabia que encontraria um certo movimento de pessoas na praça, uma vez que ela está inserida em uma área de forte atividade comercial e de serviços.

Nesse dia, não me senti estrangeiro, como aconteceu em São Paulo e Recife. Ao contrário, cheguei à Rio Branco e me senti "em casa", pois o espaço já me era familiar. Talvez por isso a sensação de brincar na rua esteve muito mais presente ao longo da composição situada. Experimentei colocar meu corpo em posições estranhas, em cima dos bancos de madeira, no chão, nos postes (Figura 4). Observei que as pessoas que passavam pela praça lançavam a mim um olhar de curiosidade, como se buscassem sentido para aquela minha movimentação. Algumas pessoas davam risadas, outras passavam sem dar muita importância. Houve ainda quem registrasse tudo com o celular, de longe. 
Figura 4 Registros da performance na Praça Rio Branco, em João Pessoa

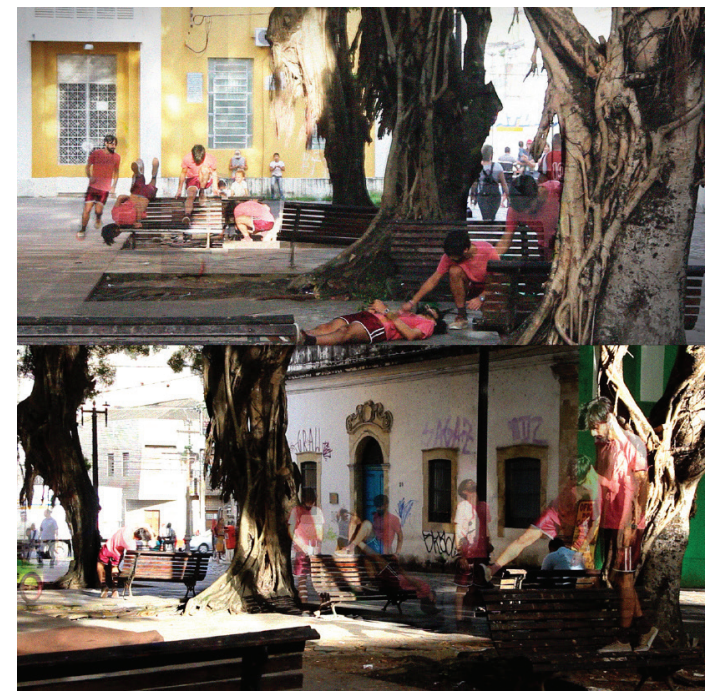

Fonte: Acervo do autor.

Enquanto isso, percebi que uma criança muito pequena começou a querer imitar o que eu fazia. Nesse momento, lembrei das crianças na Praça Roosevelt e da brincadeira de pega-pega na Praça do Diário, no Recife. Perceber que é possível recuperar esse espírito de criança, um estado de corpo muito mais aberto e maleável, foi um alívio - um corpo que procura se relacionar, que é curioso, que experimenta e que busca aprender com o outro. A minha dança me fez ser criança de novo e uma simples praça se transformou num mundo de modos possiveis de estar e conviver na cidade.

Pensar na relação entre corpo e cidade é pensar contra a hegemonia dos processos de mercantilização urbana e voltar a colocar o espaço público como lugar dissensual. Colocar o corpo em atitude no espaço, de maneira a estimular a experiência corporal/sensorial da cidade, funcionaria como uma tática para fomentar o encontro entre os indivíduos e provocar o choque entre realidades diferentes. A dança no espaço urbano responde a um desejo de despertar os habitantes da cidade para o exercício da empatia e, sobretudo, da alteridade. Mais além, o processo de criação situada pode nos fornecer pistas importantes sobre novos meios de apreender o espaço urbano a partir da experiência coletiva, revelando niveis de interação entre corpo e espaço - por meio da construção de cartografias emergentes e sensiveis da experiência urbana.

\section{REFLETE E RESPONDE: O OUE TE FAZ MOVER?}

A psicanalista e teórica brasileira Suely Rolnik (2014) explora o campo da prática cartográfica sob o viés da lógica da diferença. Assim, a autora nos introduz ao que ela entende como 
as práticas de natureza macropolítica e micropolítica. Destaco que "não se trata de uma diferença de tamanho, escala ou dimensão, mas de duas espécies radicalmente diferentes de lógica" (ROLNIK, 2014, p. 59).

A macropolítica refere-se ao plano dos territórios, um decalque da paisagem reconhecivel a priori que só cobre a camada visível. É o único plano visivel a olho nu, no qual a individuação forma unidades e a multiplicidade, totalizações. "Como uma árvore, seu traçado evolui segundo um plano de organização previsivel e controlável, um programa: raiz, eixo central e fixo; em torno do eixo, as partes" (ROLNIK, 2014, p. 60, grifo do autor). A vida, sob a lógica macropolítica, tem medo do finito ilimitado, medo de se expor aos movimentos de desterritorialização. É um pensamento obediente, baseado na manutenção de decalques. "Em outras palavras, é uma estratégia de pensamento a serviço da conservação" (ROLNIK, 2014, p. 63).

0 plano das práticas micropolíticas, em contrapartida, é movido pelo "fazer cartográfico". Assim como a dança proposta por este trabalho, o plano micropolítico acompanha os movimentos invisíveis e imprevisíveis do mundo, é feito ao mesmo tempo que o seu processo de composição. Ao contrário da cristalização das práticas macropolíticas, o plano micropolítico incorpora a mutabilidade da cartografia - dobrável, desmontável, conectável, sempre variável. 0 seu fazer deve estar atento aos artifícios do desejo, que consiste na produção do movimento de afetos - efeitos da ação de um corpo sobre outro, em seu encontro, que podem gerar atração ou repulsa. A tarefa do cartógrafo, no caso, é criar as vias para os afetos que pedem passagem (ROLNIK, 2014).

Ocupar a cidade, seja com dança ou apenas caminhando, é, além de tudo, ter autonomia e fazer micropolítica. É ser condutor da sua ação, diretor do seu espetáculo. É o exercício do direito a "dar espetáculo" como uma reafirmação do seu direito à cidade. Assim como Ana Clara Torres Ribeiro (2010, p. 32) nos revela, esse é "um direito que, para o sujeito, corresponde ao direito de ser visto, lido e conhecido em seus próprios termos e, assim, com a máscara e o roteiro de sua escolha". É ser outro e ser vários. Os atuais processos de produção da cidade, nos quais a lógica do mercado se sobrepõe às demandas da população, buscam invisibilizar a existência desse Outro. Gerar fricções, criar relações e lançar o olhar sobre as práticas dos sujeitos invisibilizados é subverter essa lógica excludente.

Por meio dessa pauta coreográfica, convido as pessoas a dançarem [com] suas cidades. Espero que mais pessoas deixem-se provocar por essas instruções abertas, registrem suas experiências e reflitam sobre o que fica gravado nos seus corpos como rastro de uma vivência corporificada. Acredito que cada um é capaz de criar sua própria pauta, seu "método" particular e sensivel de olhar para a cidade e seus espaços públicos. Não há um jeito único ou correto de se estudar a cidade. Cada cidadão pode criar seu próprio método para enxergar as questões urbanas, contanto que o Outro, e sua diversidade, esteja inserido nesse processo. Quero que sejamos sujeitos conscientes da nossa ação, para gerarmos cidades sustentáveis, sensiveis, humanas. 


\title{
To dance [with] the city: in search of emerging urban cartographies
}

\begin{abstract}
This article explores the potentialities of an artistic intervention to be performed in urban public spaces. From the findings of my master's thesis, entitled Dançar [com] a cidade: mapeamentos sensiveis da experiência urbana contemporânea (CAMBOIM, 2017), I mobilize a series of interdisciplinary concepts to reinforce an idea of city as a place of simultaneity; an idea of the body, malleable, porous to the affectations of its surroundings, in constant mutation; and an idea of dance, composed on and with the streets. Thus, I dedicate myself to the study of the relations between body and city from the experience of creating this "situated dance". Based on these concepts, I was able to conceive a choreographic guideline to dance [with] the city. This guideline, printed in the form of a lambe (a kind of poster), was affixed in some public spaces of three cities: São Paulo - SP, Recife - PE and João Pessoa - PB. In each of these cities, I followed the guideline, in order to perform the proposal of intervention. Throughout the text, I expose the concepts that gave rise to this proposal and also report the experiences of the performances engaged in the three public spaces that have been chosen. Through the choreographic guideline, I invite people to dance [with] their cities and record their experiences, suggesting them to reflect about what keeps registered in their bodies as a sign of a lived experience.
\end{abstract}

Keywords: Situated dance. Body. Public space. Emerging urban cartographies. Choreographic guideline.

\section{REFERÊNCIAS}

ARDENNE, P. Un art contextuel. Paris: Flammarion, 2002.

BOURRIAUD, N. Estética relacional. São Paulo: Martins Fontes, 2009.

BRITTO, F. D.; JACQUES, P. B. Cenografias e corpografias urbanas: um diálogo sobre as relações entre corpo e cidade. Cadernos PPG-AU, Salvador, volume especial, n. 7, p. 79-86, 2008.

CAMBOIM, I. L. M. Dançar [com] a cidade: mapeamentos sensiveis da experiência urbana contemporânea. 2017. Dissertação (Mestrado em Arquitetura e Urbanismo) - Universidade Federal da Paraiba, João Pessoa, 2017.

DEBORD, G.-E. Teoria da deriva. In: JACQUES, P. B (org.). Apologia da deriva: escritos situacionistas sobre a cidade. Rio de Janeiro: Casa da Palavra, 2003. p. 87-91.

GREINER, C. O corpo: pistas para estudos interdisciplinares. São Paulo: Annablume, 2005.

HARVEY, D. Cidades rebeldes: do direito à cidade à revolução urbana. São Paulo: Martins Fontes, 2014.

HARVEY, D. Espaços de esperança. 4. ed. São Paulo: Edições Loyola, 2011.

HÉLIO Oiticica. Direção: César Oiticica Filho. Belo Horizonte: Guerrilha Filmes, 2012. (94 min). 
INTERNACIONAL SITUACIONISTA. Questões preliminares à construção de uma situação. In: JACQUES, P. B (org.). Apologia da deriva: escritos situacionistas sobre a cidade. Rio de Janeiro: Casa da Palavra, 2003. p. 62-64.

JACQUES, P. B. Corpografias urbanas. Arquitextos, São Paulo, ano 8, n. 093.07, fev. 2008. Disponivel em: https://vitruvius.com.br/revistas/read/arquitextos/08.093/165. Acesso em: 5 jul. 2021.

JACQUES, P. B. Táticas profanatórias de espaços urbanos. In: URIARTE, U. M.; CARVALHO, M. J. (org.). Panoramas urbanos: usar, viver e construir Salvador. Salvador: Edufba, 2014. p. 15-29.

LEFEBVRE, H. La production de l'espace. 4. ed. Paris: Éditions Anthropos, 2000.

LEFEBVRE, H. O direito à cidade. Lisboa: Letra Livre, 2012.

MORAIS, C. A dança in situ no espaço urbano. São Paulo: Lince, 2015.

MORAIS, L. de A. Corpomapa: o dançarino e o lugar na composição situada. 2015. Tese (Doutorado em Artes Cênicas) - Escola de Teatro, Universidade Federal da Bahia, Salvador, 2015.

PALLAMIN, V. M. Arte urbana: São Paulo: região central (1945-1998): obras de caráter temporário e permanente. São Paulo: Annablume, 2000.

PASSOS, J. C. Rolf Gelewski e a improvisação na criação em dança: formas, espaço e tempo. Curitiba: Prismas, 2015.

RIBEIRO, A. C. T. Dança de sentidos: na busca de alguns gestos. In: JACQUES, P. B.; BRITTO, F. D. (org.) Corpocidade: debates, ações e articulações. Salvador: Edufba, 2010. p. 24-41.

RIBEIRO, A. C. T. et al. Cartografia da ação e a juventude na cidade: trajetórias do método. In: RIBEIRO, A. C. T.; CAMPOS, A.; SILVA, C. A. (org.). Cartografia da ação e movimentos da sociedade: desafios das experiências urbanas. Rio de Janeiro: Lamparina, 2011. p. 30-42.

ROLNIK, S. Cartografia sentimental: transformações contemporâneas do desejo. 2. ed. Porto Alegre: Sulina: UFRGS, 2014.

SANTOS, M. Técnica, espaço, tempo: globalização e meio técnico-científico informacional. 5. ed. São Paulo: Edusp, 2013.

WEBER, S. Um modo particular de composição: a improvisação. In: ALMEIDA, M. A cena em foco: artes coreográficas em tempos líquidos. Brasilia: IFB, 2015. p. 11-22. 